\title{
A compensação financeira e o desenvolvimento de municípios impactados por hidrelétricas: os indicadores sociais de Paranã e São Salvador do Tocantins
}

A matriz energética do Brasil conta com participação expressiva das usinas hidrelétricas, responsáveis por mais da metade a energia elétrica gerada no país. Este empreendimentos são exaltados pela política nacional do setor por assegurarem menor custo de produção e impacto ambiental se comparados a outras fontes de geração elétrica, além de contribuírem para o desenvolvimento regional e local. Entre as vantagens proporcionadas pela instalação de uma hidrelétrica, os estudos técnicos enfatizam ganhos permanentes a estados e municípios sedes por meio da CFURH - Compensação Financeira pelo Uso de Recursos Hídricos, cujos recursos devem favorecer a melhoria da infraestrutura, dos serviços públicos e, consequentemente, da qualidade de vida das comunidades. No entanto, a inexistência de uma legislação que vincule a compensação financeira à receita municipal e que oriente a sua aplicação abre margem para o uso do dinheiro em outros fins que não sejam em prol de melhorias para a sociedade. Este trabalho teve o objetivo de apontar o total de recursos provenientes de CFURH destinados, entre 2006 até 2016, aos municípios de Paranã e São Salvador do Tocantins, no Estado do Tocantins, Brasil, impactados por empreendimentos hidrelétricos, correlacionando os valores recebidos com o desenvolvimento social destas localidades. Os resultados evidenciam que, apesar do incremento da CFURH, os dois municípios exibem indicadores sociais insatisfatórios, com deficiências de infraestrutura, na oferta de equipamentos públicos, nas condições de moradia e na assistência à saúde, bem como limitada oferta de oportunidades de evolução educacional e profissional de suas populações.

Palavras-chave: Compensação Financeira; Usinas Hidrelétricas; Desenvolvimento Socioeconômico; Paranã; São Salvador do Tocantins.

\section{Financial compensation and development of municipalities impacted by hydroelectric plants: the social indicators of Paranã and São Salvador do Tocantins}

\begin{abstract}
The Brazilian electricity matrix has an expressive participation of hydroelectric plants, responsible for more than half of the electric power produced in the country. These ventures are fomented by the national industry policy for ensuring lower environmental impact and production costs if compared to other sources of power generation, as well as for contributing to regional and local development. Among the advantages provided by the construction of a hydroelectric plant, the technical studies emphasize permanent benefits to state and municipal governments through a Financial Compensation for the Use of Water Resources CFURH - Compassion Financier for Use Recourses Hydrinos, whose resources should favor the improvement of infrastructure, public services and, consequently, quality of life. However, the absence of laws linking financial compensation to municipal revenue and guiding its application opens up a scope for using the funds for purposes other than society development. The objective of this work is to estimate the total resources from CFURH destined for the municipalities of Paranã and São Salvador do Tocantins, in the State of Tocantins, Brazil, between 2006 and 2016, impacted by hydroelectric projects, correlating the values received with the development of these places. The results show that, in spite of the increase in CFURH, both municipalities have unsatisfactory social indicators, with deficiencies in infrastructure, in the provision of public facilities, in housing conditions and health care, as well as limited educational and professional opportunities for the local population.
\end{abstract}

Keywords: Financial Compensation; Hydroelectric Plants; Socioeconomic Development; Paranã; São Salvador do Tocantins.

Topic: Desenvolvimento, Sustentabilidade e Meio Ambiente

Reviewed anonymously in the process of blind peer.

Kiara Lubick Silva Maldaner

Universidade Federal do Tocantins, Brasil http://lattes.cnpq.br/0750924602283457 http://orcid.org/0000-0002-1804-8905

kiaralubick@yahoo.com.br

Alberto Akama (it)

Universidade de São Paulo, Brasil

http://lattes.cnpq.br/9905086086253867

http://orcid.org/0000-0003-0209-770X

aakama@gmail.com
Received: $10 / 02 / 2019$

Approved: 25/03/2019
Referencing this:

MALDANER, K. L. S.; AKAMA, A.. A compensação financeira e o desenvolvimento de municípios impactados por hidrelétricas: os indicadores sociais de Paranã e São Salvador do Tocantins. Revista Ibero Americana de Ciências Ambientais, v.10, n.2, p.271-283, 2019. DOI: http://doi.org/10.6008/CBPC2179-6858.2019.002.0023 


\section{INTRODUÇÃO}

A fonte hidráulica constitui-se a principal geradora de energia elétrica do Brasil. No contexto da matriz energética nacional, $75,6 \%$ de toda a energia elétrica gerada é proveniente desta fonte renovável, somando-se a produção oriunda de 1.403 empreendimentos hidrelétricos, subdivididos em 217 UHEs Usinas Hidrelétricas e 1.124 PCHs e CGH - Pequenas Centrais Hidrelétricas e Centrais Geradoras Hidrelétricas, além de 62 CGH GD - Centrais Geradoras Hidrelétricas de Geração Distribuída ${ }^{1}$. Destes, a maior contribuição é proveniente das UHEs. Os empreendimentos desta natureza em operação acumulam capacidade instalada de $98.287 \mathrm{MW}$, o que representa 60,1\% do total da capacidade instalada, de $163.441 \mathrm{MW}$, para a geração de eletricidade no país em dezembro de 2018 (BRASIL, 2018).

Este desempenho das UHEs é fruto de investimentos maciços no setor. Especialmente a partir da segunda metade do Século $X X$, grande aporte de recursos financeiros foi destinado à implantação de hidrelétricas, consideradas estratégicas ao modelo de desenvolvimento econômico brasileiro (GOMES et al., 2017), especialmente em função de suas vantagens comparativas em relação a outras fontes geradoras de energia (BERMANN, 2007). Contribuiu para isso, o fato do país possuir um território com um vasto potencial hídrico a ser explorado, acrescido por conhecimento, expertise e tecnologias acessíveis à engenharia local para a construção de usinas (FARIA et al., 2012). Bermann destaca que "o aproveitamento da água para a geração de energia elétrica encontrou no território brasileiro um importante campo para o desenvolvimento e consolidação da engenharia nacional" (BERMANN, 2007).

No discurso governista, são diversas as justificativas em incentivo à implantação de UHEs. Uma delas enfatiza o potencial destes empreendimentos para substituírem as usinas termoelétricas (GOMES et al., 2017), que empregam recursos limitados, como derivados de petróleo, gás natural e carvão (FARIA et al., 2012) e, portanto, de maior influência, por conta da emissão de poluentes, sobre as mudanças climáticas globais. Mas um argumento em especial estimula à construção de sentidos em torno das UHEs ao idealizálas como indutoras de desenvolvimento socioeconômico das localidades e regiões onde estão inseridas. Além da criação de postos de trabalho e aumento a arrecadação de impostos, os estudos técnicos enfatizam como vantagem proporcionada pela instalação de uma UHE o pagamento da CFURH - Compensação Financeira pelo Uso de Recursos Hídricos, um ganho permanente para as prefeituras e cuja aplicação deve favorecer a melhoria da infraestrutura, dos serviços e políticas públicas e, consequentemente, da qualidade de vida e promoção social das populações humanas das áreas afetadas (BRASIL, 2015).

Estas previsões, no entanto, não necessariamente se traduzem em realidade. A inexistência de uma legislação que vincule a CFURH à receita municipal e que oriente a sua aplicação abre margem para o uso do dinheiro em outros fins que não sejam em prol de melhorias para a sociedade (GOMES et al., 2017); (SILVA, 2007). Isso significa que, na prática, a influência da CFURH para o avanço econômico e social deve ser analisada de acordo com a especificidade de cada município ou região. Este trabalho se propõe a apontar o

\footnotetext{
${ }^{1}$ Para efeito de classificação, a Agência Nacional de Energia Elétrica considera: CGH (potência instalada até 3 MW); PCH (superior a 3 MW e igual ou inferior a $30 \mathrm{MW}$ ); e UHE (com potência instalada superior a $30 \mathrm{MW}$ ) (EPE, 2016).
} 
A compensação financeira e o desenvolvimento de municípios impactados por hidrelétricas: os indicadores sociais de Paranã e São Salvador do Tocantins

MALDANER, K. L. S.; AKAMA, A.

total em CFURH provenientes de usinas hidrelétricas destinadas aos municípios de Paranã e São Salvador do Tocantins, no Estado do Tocantins, Brasil, entre os anos de 2006 e 2016, correlacionando os valores com o desempenho socioeconômico destas localidades. No campo científico, ainda há uma carência de estudos com ênfase em analisar se e/ou como as compensações financeiras no Brasil atendem as perspectivas dos estudos técnicos convertendo-se em benefícios para as comunidades em termos de infraestrutura e qualidade de vida. Especialmente na região Amazônica, área de localização do Tocantins e que nas últimas duas décadas tornou-se alvo de grandes projetos hidrelétricos, tornam-se necessárias investigações quanto aos efeitos da política desenvolvimentista sobre o progresso socioeconômico das populações.

\section{REVISÃO TEÓRICA}

É comum os estudos de viabilidade enfatizarem benefícios socioeconômicos proporcionados aos municípios e regiões afetados pela implantação de uma UHE. As análises técnicas ressaltam especialmente como vantagem o incremento na arrecadação municipal gerada pela CFURH, valor com o qual as localidades poderão contar regularmente (EPE, 2007; BRASIL, 2015). O discurso dominante constrói sentidos, sobrevalorizando e propagando a imagem das compensações financeiras como promovedoras de desenvolvimento local (PULICE et al., 2017).

Conforme a ANEEL- Agência Nacional de Energia Elétrica- tem-se por compensação financeira "um ressarcimento pela ocupação de áreas por usinas hidrelétricas e um pagamento pelo uso da água na geração de energia" (ANEEL, 2005). A CFURH corresponde a 7\% do valor da energia gerada, sendo que 6,25\% deste montante é pago pelos concessionários de energia à União, tendo como beneficiários o MMA- Ministério de Minas e Energia, o MME- Ministério do Meio Ambiente e o Fundo Nacional de Desenvolvimento Tecnológico, aos estados, Distrito Federal e municípios sedes das UHEs com potência acima de 30MW e também aos municípios atingidos pelas águas represadas (BRASIL, 2018). O valor indenizado é proporcional à área alagada pela UHE. Os outros $0,75 \%$ são destinados ao MME para aplicação em políticas públicas no âmbito dos recursos hídricos (BRASIL, 2018)². Estes percentuais estão detalhados na figura 1.

A CFURH foi instituída pelo artigo no 20 da Constituição Federal de 1988 e regulamentada pela Lei no 7.990/1989 (ANEEL, 2005). Os percentuais de distribuição foram estabelecidos pela Lei 8.001/1990 e atualizado pela Lei 13.661/2018 (BRASIL, 2018). O valor a ser pago é calculado mensalmente de acordo com a energia gerada pela UHE (ANEEL, 2007). Na perspectiva da legislação, os recursos oriundos da compensação devem ser utilizados em função da promoção das condições sociais e econômicas dos municípios, orientando-se seu investimento em áreas prioritárias, como saúde, infraestrutura, educação e segurança. Entretanto, falta a este mecanismo de compartilhamento de benefícios uma regulamentação que vincule o uso do dinheiro para estes fins, o que deixa a critério do gestor municipal definir como o recurso será aplicado

${ }^{2}$ Até maio/2018, a distribuição dos percentuais da CFURH correspondia a $10 \%$ para a União, $45 \%$ para os estados e $45 \%$ para os municípios, além de
$0,75 \%$ para a ANA (ANEEL, 2005). A Lei 13.661/2018 atualizou os percentuais para os números acima citados (BRASIL, 2018). 
(GOMES et al., 2017; SILVA, 2007). A única restrição expressa na lei diz respeito ao uso da CFURH para pagamento de dívidas e de salários dos servidores públicos (SILVA, 2007; BRASIL, 2005).

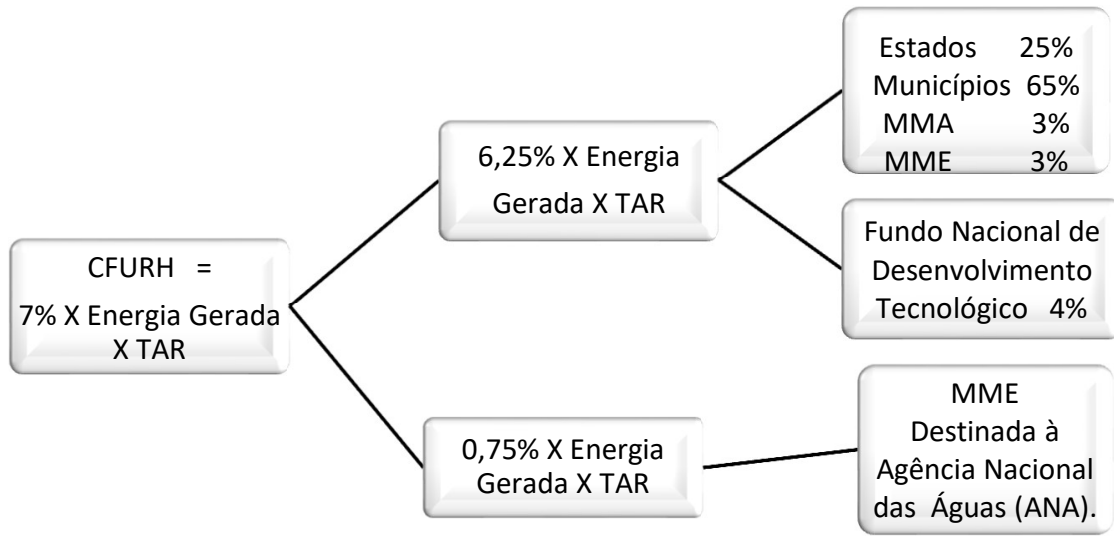

Figura 1: Beneficiários da CFURH e percentuais conforme a legislação.

Esta falha na definição de critérios põe em risco o objetivo proposto para este recurso, que seria "o fomento ao desenvolvimento socioambiental da região e na adequação da estrutura social e econômica local às novas condições impostas pela construção da usina hidrelétrica" (SILVA, 2007). Na opinião de Cerner (2008), estes recursos são mal aplicados, além de insuficientes para alcançar a finalidade de gerar melhorias para a comunidade. Tal carência de efetividade e eficiência ficou evidenciada por Sterchile et al. (2008) em relação à aplicação de repasses financeiros derivados da UHE Itaipu Binacional à prefeitura de Santa Helena, no Estado do Paraná, onde foi constada a ausência de planejamento para a aplicação. Nesta localidade, os recursos oriundos dos royalties, que neste caso equivalem à compensação financeira (ANEEL, 2005), têm sido investidos em ações de maior visibilidade perante a população, como na saúde, pavimentação e compra de equipamentos, mas não amparam uma das problemáticas mais urgentes, que é o desemprego e a execução de políticas voltadas à qualificação profissional atrelada à educação, evidenciando-se uma contradição entre os valores repassados e as condições locais de trabalho (STERCHILE et al., 2008).

Conclusão semelhante foi relatada em pesquisa envolvendo um grupo de UHEs do complexo PelotasUruguai. O agravamento de desigualdades sociais, do trabalho infantil e dos problemas de esgotamento sanitário nos municípios afetados pelas UHEs de Itá, Barra Grande, Machadinho e Campos Novos sobrepõese à efetividade da aplicação da CFRH em termos de compartilhamento de benefícios (GOMES et al., 2017). Já trabalho junto a municípios afetados pela UHE Tucuruí, no Estado do Pará, revelou "melhorias nos índices sociais - IDH acesso à água encanada e à energia elétrica - e nos índices econômicos - renda per capita, PIB e redução da pobreza" (SILVA, 2007), sinalizando que neste caso a CFURH cumpriu com a meta de converterse em benefícios para as comunidades. Entretanto, fato interessante desta investigação é que, ao contrário do que se imagina, foram os municípios que recebem menor percentual de aporte financeiro que obtiveram os mais elevados índices sociais. É o caso de Nova Ipixuna, que apresentou o melhor desempenho, apesar de receber os menores valores em CFURH. Por outro lado, os municípios com pior desempenho social foram justamente os que recebem maior aporte em compensação - Jacundá, Itupiranga e Tucuruí - mas que pouco convertem a verba em benefícios. Em relação a estes municípios, a pesquisa concluiu que "Tucuruí recebe 
A compensação financeira e o desenvolvimento de municípios impactados por hidrelétricas: os indicadores sociais de Paranã e São Salvador do

valores altos de Compensação Financeira, mas gasta menos do que recebe em investimentos para o município. Da mesma forma, o município de Jacundá tem empregado apenas $8 \%$ da receita municipal em investimento" (SILVA, 2007). Os estudos evidenciam, de forma clara e contundente, que tão importante quanto a disponibilidade do dinheiro é o planejamento para o uso dos recursos condizente com as necessidades reais da população. Corrobora com os argumentos de que o devido planejamento, a fiscalização e a aplicação em áreas prioritárias são essenciais para que, de fato, as verbas provenientes de CFURH contribuam com a promoção econômica e social dos municípios impactados pelas UHEs.

\section{METODOLOGIA}

O procedimento metodológico adotado na investigação foi a análise documental, que permite a identificação, a verificação e a apreciação de documentos, explorando relatórios técnicos de origem secundária (MOREIRA, 2005). Foi realizado levantamento do total de recursos provenientes de CFURH destinados aos municípios de Paranã e São Salvador do Tocantins entre os anos de 2006 e 2016. As informações foram extraídas dos relatórios de CFURH da ANEEL, que disponibiliza os valores mensais e anuais das compensações (ANEEL, 2018). Num segundo passo, otimizando correlacionar os valores provenientes das compensações com o desenvolvimento humano, econômico e social de Paranã e São Salvador do Tocantins foram identificados três diferentes indicadores sociais das localidades, sendo: o IDH - Índice de Desenvolvimento Humano; o IBEU- Índice do Bem-Estar Urbano Municipal; e, o Índice de Progresso Social na Amazônia Brasileira - IPS Amazônia 2014.

O IDH, criado pela ONU no início da década de 1990, avalia a qualidade de vida e o desenvolvimento socioeconômico de uma população a longo prazo e relacionados às dimensões renda, educação e saúde, a partir de informações coletadas e divulgadas pelo Censo Demográfico Brasileiro. A metodologia estabelece pontuações que vão de 0 à 1 para classificar as faixas de desenvolvimento humano, considerando: 0.800 a 1, muito alto desenvolvimento; 0.700 a 0.799 , alto; 0.600 a 0.699 médio; 0.500 a 5.999 baixo; e, inferior a 0.500, muito baixo desenvolvimento humano (PNUD, 2013). Para análise da evolução, foi explorado o IDH de Paranã e São Salvador do Tocantins referente aos anos de 2000 e 2010.

Já o IBEU Municipal foi desenvolvido pelo Observatório das Metrópoles do INCT- Instituto Nacional de Ciência e Tecnologia. A metodologia calcula a qualidade do bem-estar urbano dos municípios brasileiros a partir de dados do Censo Demográfico de 2010, avaliando as seguintes dimensões: Mobilidade Urbana (D1), Condições Ambientais Urbanas (D2), Condições Habitacionais Urbanas (D3), Atendimentos de Serviços Coletivos Urbanos (D4) e Infraestrutura Urbana (D5). A pontuação, ou valor, atribuído às dimensões variam de zero a 1 , de modo que quanto mais próximo de 1 , melhores são as condições urbanas, e quanto mais próximo de zero, piores são estas condições. A interpretação dos valores parte do seguinte princípio: de zero a 0,500, condições muito ruins; de 0,501 a 0,700 condições ruins; de 0,701 a 0,800 condições médias; de 0,801 a 0,900 condições boas; e, de 0,901 a 1, condições muito boas (OBSERVATÓRIO DAS METRÓPOLES, 2016). A dimensão mobilidade urbana avalia o tempo de deslocamento casa-trabalho, enquanto a dimensão 
A compensação financeira e o desenvolvimento de municípios impactados por hidrelétricas: os indicadores sociais de Paranã e São Salvador do Tocantins

condições ambientais urbanas é construída a partir de três indicadores: arborização no entorno dos domicílios, esgoto a céu aberto e lixo acumulado no entorno dos domicílios. Por sua vez, a dimensão infraestrutura apresenta a análise dos indicadores: iluminação pública, pavimentação, calçada, meio/fio, bueiro ou boca de lobo, rampa para cadeirantes e logradouros. A dimensão condições habitacionais verifica a qualidade do material estrutural das moradias e a aglomeração de domicílios, além da quantidade de pessoas e de dormitórios por moradia. Por fim, a dimensão serviços coletivos urbanos avalia serviços essenciais para o bem-estar, analisando o atendimento adequado de água, esgotamento sanitário, energia elétrica e coleta adequada de lixo.

O terceiro índice, o IPS Amazônia 2014, foi desenvolvido pelas entidades Imazon e Progresso Social Brasil. Utilizando dados públicos disponíveis na internet por instituições governamentais ou nãogovernamentais, mensura a performance social e ambiental de uma determinada localidade, abordando três dimensões consideradas de alto nível de importância para o progresso social: as 'Necessidades Humanas Básicas', os 'Fundamentos de Bem-Estar' e as 'Oportunidades'. Referentes a estas dimensões, são analisados um total de 43 indicadores de 12 componentes, para os quais são atribuídas pontuações numa escala que varia de 0 a 100, sendo que quanto maior a pontuação, melhor o desempenho (IMAZON et al., 2014). A dimensão Necessidades Humanas Básicas afere o grau em que a comunidade satisfaz as necessidades essenciais de sua população em termos de alimentação suficiente, cuidados médicos básicos, acesso à água potável, moradia adequada, serviços públicos básicos e segurança, enquanto os Fundamentos de Bem-Estar indicam o acesso à educação básica e fundamental, a qualidade da educação, acesso à comunicação e informação e à saúde em termos de expectativa de vida ao nascer, mortalidade por doenças crônicas e respiratórias, obesidade e taxa de suicídio. Esta dimensão também mede a sustentabilidade dos ecossistemas, o que inclui o cuidado com o ar, com a água e com a terra. A última dimensão, Oportunidades, mede o grau de liberdade da população, diversidade partidária, tolerância, inclusão e violência contra indígenas, além do acesso à cultura, esporte e lazer, ao ensino superior, à educação feminina e às oportunidades de conhecimento e de desenvolvimento de habilidades (IMAZON et al., 2014).

\section{Caracterização da área da pesquisa}

O município de Paranã possui área de 1120,216 km², com uma população estimada em 2018 de 10.461 habitantes, enquanto São Salvador do Tocantins tem área de 1422,033 km² e 3.070 habitantes. Localizados na região Sudeste do Estado do Tocantins, no Brasil, os municípios contam com infraestrutura básica, com água encanada, pavimentação das principais ruas e avenidas, hospitais municipais para atendimentos de baixa complexidade e unidades básicas de saúde (TOCANTINS, 2012). A estrutura da educação é composta por creches municipais e escolas municipais e estaduais. $O$ ensino superior é dependente de instituições de municípios polos da região, a exemplo da cidade de Arraias, distante cerca de 123 km de Paranã e 178 km de São Salvador. 
Tanto Paranã quanto São Salvador do Tocantins foram impactados pela implantação de UHEs construídas ao longo do curso do rio Tocantins ${ }^{3}$, sendo que duas delas localizam-se nas áreas de abrangência destes municípios. O mapa UHEs do Rio Tocantins, figura 2, dá uma ideia do curto espaço físico, apenas cerca de $100 \mathrm{~km}$ de distância, entre um empreendimento e outro. A primeira usina, a UHE Peixe Angical, começou a ser construída em 2002 e teve suas operações iniciadas em 2006, com capacidade de geração de 452MW de energia elétrica. A UHE São Salvador está em operação desde o ano de 2009, com capacidade instalada de 243MW. Fica localizada entre os municípios de São Salvador e Paranã (BRASIL, 2015).

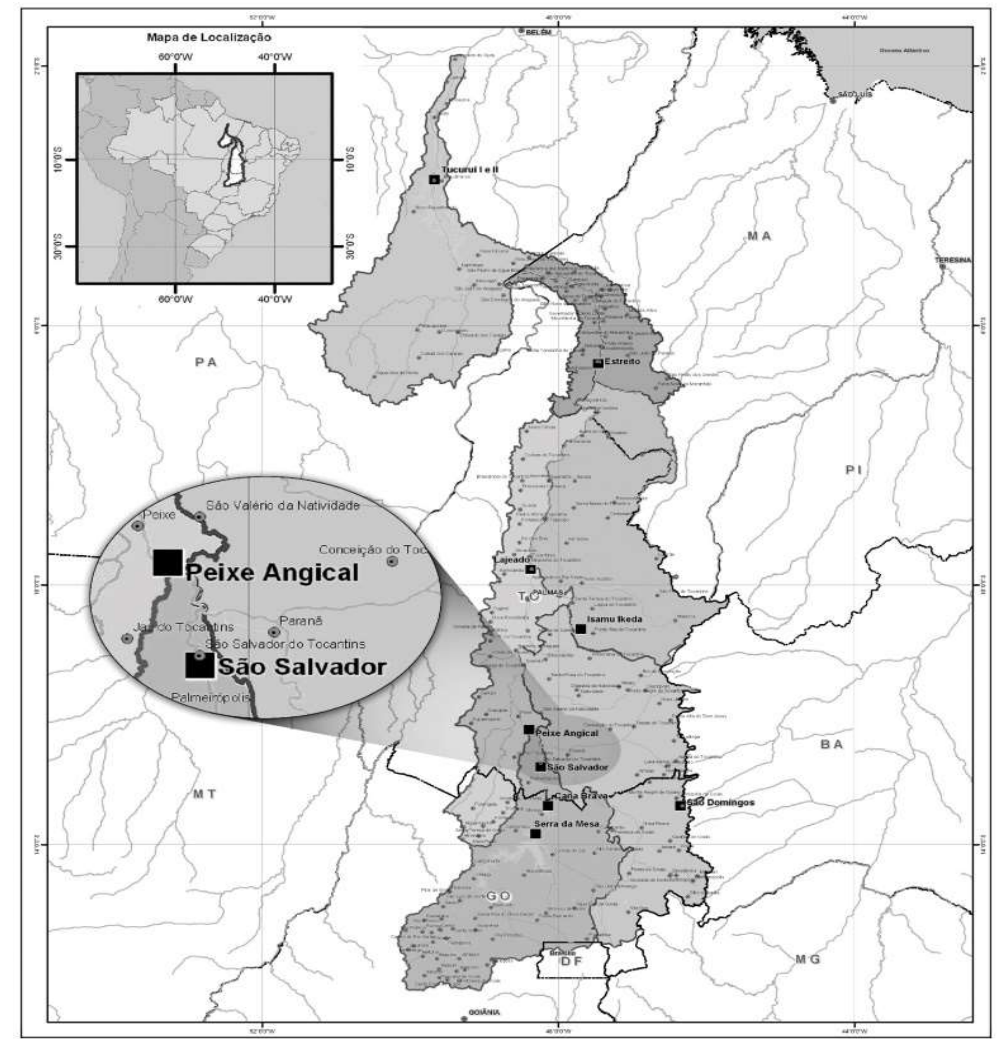

Figura 2: Mapa UHEs do Rio Tocantins.

\section{RESULTADOS}

Na tabela 1 é apresentado o montante, em Reais, destinado a Paranã e São Salvador do Tocantins entre os anos de 2006 até 2016. Os valores correspondem ao total das CFURHs provenientes de UHEs que impactam os dois municípios, o que inclui, além das hidrelétricas Peixe Angical e São Salvador, a UHE Tucuruí, UHE Estreito e UHE Luís Eduardo Magalhães. No entanto, o grosso das compensações, em média $90 \%$ da totalidade, reservado para Paranã e São Salvador do Tocantins refere-se à UHE Peixe Angical e à UHE São Salvador.

Percebe-se, neste período, um razoável incremento, de pouco mais de $\mathrm{R} \$ 25$ milhões, à receita de Paranã, o dobro do valor designado para São Salvador do Tocantins, que recebeu R\$ 12,3 milhões em CFURH.

\footnotetext{
${ }^{3}$ Um total de sete UHEs estão instaladas no curso do rio Tocantins : Serra da Mesa, Cana Brava, São Salvador do Tocantins, Peixe Angical, Luís Eduardo Magalhães, Estreito e Tucuruí (EPE, 2007). Além destas, o rio também comporta PCHs, como Isamu Ikeda e São Domingos também identificadas no mapa.
} 
A compensação financeira e o desenvolvimento de municípios impactados por hidrelétricas: os indicadores sociais de Paranã e São Salvador do

Isso se dá em função do percentual da área alagada que, tanto em relação à UHE Peixe Angical quanto à UHE São Salvador, atingiu em maior dimensão o território de Paranã.

Tabela 1: Repasses de CFURH.

\begin{tabular}{|l|l|}
\hline Municípios & Total de 2006 até 2016 \\
\hline Paranã & $\mathrm{R} \$ 25.106 .067,52$ \\
\hline São Salvador & $\mathrm{R} \$ 12.323 .174,41$ \\
\hline
\end{tabular}

Considerando-se o IDH total, os municípios pesquisados obtiveram relativo progresso entre os anos de 2000 e 2010, como mostra a tabela 2. O desempenho mais satisfatório foi obtido por São Salvador do Tocantins, que ultrapassou o patamar de muito baixo desenvolvimento para enquadrar-se na condição de médio desenvolvimento humano (IDH 0.605). Já Paranã, que também mostrava muito baixo desenvolvimento humano, evoluiu, mas ainda manteve-se linha do baixo desenvolvimento humano (IDH 0.595).

Tabela 2 : IDH.

\begin{tabular}{|l|l|l|}
\hline & ANO & ANO \\
\hline Municípios & $\mathbf{2 0 0 0}$ & $\mathbf{2 0 1 0}$ \\
\hline Paranã & 0.334 & 0.595 \\
\hline São Salvador do Tocantins & 0.419 & 0.605 \\
\hline
\end{tabular}

Nos dois municípios, o componente Longevidade (saúde) obteve melhor desempenho, seguido por Renda e Educação. De forma detalhada, os municípios apresentaram os seguintes índices de acordo com as dimensões: Paranã: Longevidade (0,777); Renda (0.588); e Educação (0.461). São Salvador: Longevidade (0.794); Renda (0.592); e Educação (0.471) (PNUD, 2013).

As pontuações por dimensão do IBEU Municipal são detalhadas na tabela 3. Observa-se que os municípios investigados enquadraram-se na faixa de muito boas condições de Mobilidade Urbana (D1), o que se explica pela reduzida dimensão territorial e contingente populacional de suas áreas urbanas, que acomodam 1.258 domicílios em Paranã e 460 em São Salvador do Tocantins (IBGE, 2012) ${ }^{4}$. Na segunda variável, Condições Ambientais Urbanas (D2), um excelente desempenho também foi obtido por Paranã, com 0,940 pontos, enquanto São Salvador do Tocantins se restringiu à média condição ambiental $(0,713)$. Este componente é indicativo da efetividade da limpeza urbana avaliando, além da arborização no entorno dos domicílios, a existência de esgoto a céu aberto e de lixo acumulado próximo às residências.

Na variável D3, Condições Habitacionais Urbanas, tanto Paranã quanto São Salvador do Tocantins mantêm-se na faixa mediana, com pontuações 0,735 e 0,752, respectivamente. Desempenhos negativos são predominantes no quesito Atendimentos Coletivos Urbanos (D4), o que se traduz em variáveis abaixo de 0,700: Paranã com 0,571 e São Salvador do Tocantins com 0,580, revelando deficiência na oferta de serviços públicos. Situação crítica também é diagnosticada na variável Infraestrutura Urbana (D5), na qual os dois municípios apresentam média abaixo de 0,500, o significa condições muito ruins de infraestrutura. Em

\footnotetext{
4 Ambos os municípios apresentam baixa densidade populacional. São 0,92hab./m² em Paranã e 2,05hab/km² em São Salvador do Tocantins. Interessante observar grande concentração de domicílios na zona rural. Em Paranã, mais da metade, são 1.614 domicílios rurais contra 1.258 urbanos. São Salvador contabiliza 460 domicílios urbanos e 367 rurais (IBGE, 2012). Isso se dá por conta da forte vocação agropecuária dos dois municípios.
} 
A compensação financeira e o desenvolvimento de municípios impactados por hidrelétricas: os indicadores sociais de Paranã e São Salvador do Tocantins

MALDANER, K. L. S.; AKAMA, A

termos gerais, e a partir da média das cinco dimensões acima detalhadas, Paranã $(0,697)$ e São Salvador do Tocantins $(0,694)$ foram classificados pelo IBEU Municipal em condições ruins de bem-estar urbano.

Tabela 3: IBEU.

\begin{tabular}{|l|l|l|l|l|l|l|}
\hline MUNICIPAL & & & & & & \\
\hline Municípios & DD1 & DD2 & DD3 & DD4 & DD5 & IBEU Total \\
\hline Paranã & 00,920 & 00,940 & 00,735 & 00,571 & 00,318 & 0,697 \\
\hline São Salvador do Tocantins & 00,992 & 00,713 & 00,752 & 00,580 & 00,430 & 0,694 \\
\hline
\end{tabular}

Por fim, o IPS Amazônia de Paranã e São Salvador do Tocantins é apresentado nas tabelas 4 e 5 . A dimensão Oportunidades apresentou o pior desempenho nos dois municípios. Chamam a atenção nesta dimensão os resultados dos componentes 'tolerância e inclusão' e 'acesso à educação superior'. O primeiro, por relevar violência contra indígenas e contra a mulher. $O$ segundo, por conta da baixa pontuação obtida, de apenas 18,61 (Paranã) e 20,93 (São Salvador do Tocantins).

Tabela 4: IPS Amazônia Paranã.

\begin{tabular}{|c|c|c|c|c|c|}
\hline \multicolumn{6}{|c|}{ Pontuação Total } \\
\hline \multicolumn{6}{|l|}{ Índice de Progresso Social: } \\
\hline & Pontuação| & \multicolumn{2}{|c|}{ Pontuação| } & \multicolumn{2}{|r|}{ Pontuação } \\
\hline Necessidades Humanas Básicas & 53,72 & Fundamentos para o Bem-Estar & 57,46 & Oportunidades & 47,34 \\
\hline Nutrição e cuidados médicos básicos & 75,93 & Acesso ao conhecimento básico & 55,43 & Direitos individuais & 42,68 \\
\hline \multirow{5}{*}{$\begin{array}{l}\text { Subnutrição } \\
\text { Mortalidade por desnutrição } \\
\text { Mortalidade materna } \\
\text { Mortalidade infantil até } 5 \text { anos } \\
\text { Mortalidade por doenças infecciosas }\end{array}$} & & \multirow{4}{*}{$\begin{array}{l}\text { Analfabetismo } \\
\text { Acesso ao ensino médio } \\
\text { Qualidade da educação } \\
\text { Acesso ao ensino fundamental }\end{array}$} & & \multicolumn{2}{|l|}{ Diversidade partidária } \\
\hline & & & & \multicolumn{2}{|l|}{ Mobilidade urbana } \\
\hline & & & & \multicolumn{2}{|l|}{ Pessoas ameaçadas } \\
\hline & & & & Liberdade individual e de escolha & 64,93 \\
\hline & & Acesso à informação e comunicação & 75,66 & Trabalho infantil & \\
\hline Água e saneamento & 21,80 & Conexão de voz & & \multirow{3}{*}{\multicolumn{2}{|c|}{$\begin{array}{l}\text { Gravidez na intância e adolescência } \\
\text { Vulnerabilidade familiar } \\
\text { Acesso à cultura, esporte e lazer }\end{array}$}} \\
\hline \multicolumn{2}{|l|}{$\begin{array}{l}\text { Abastecimento de água } \\
\text { Esgotamento sanitário }\end{array}$} & Conexão de dados de internet móvel & & & \\
\hline Esgotamento sanitário & & Saúde e bem-estar & 30,90 & & \\
\hline \multicolumn{2}{|l|}{ Saneamento rural } & \multicolumn{2}{|l|}{ Mortalidade por doenças crônicas } & Tolerância e inclusão & 63,16 \\
\hline Moradia & 53,98 & Expectativa de vida ao nascer & & \multirow{2}{*}{\multicolumn{2}{|c|}{$\begin{array}{l}\text { Violência contra a mulher } \\
\text { Violência contra indígenas }\end{array}$}} \\
\hline Moradia adequada & & Obesidade & & & \\
\hline \multicolumn{2}{|l|}{ Acesso à energia elétrica } & \multicolumn{2}{|l|}{ Mortalidade por doenças respiratórias } & \multicolumn{2}{|l|}{ Desigualdade racial na educação } \\
\hline \multicolumn{2}{|l|}{ Coleta de lixo } & \multicolumn{2}{|l|}{ Suicídio } & Acesso à educação superior & 18,61 \\
\hline Segurança pessoal & 63,19 & Sustentabilidade dos ecossistemas & 67,87 & \multirow{2}{*}{\multicolumn{2}{|c|}{$\begin{array}{l}\text { Pessoas com ensino superior } \\
\text { Educação feminina }\end{array}$}} \\
\hline Homicídios & & Desmatamento recente & & & \\
\hline \multicolumn{2}{|l|}{ Mortes por acidente no trânsito } & Áreas degradadas & & \multirow{4}{*}{\multicolumn{2}{|c|}{ Frequência ao ensino superior }} \\
\hline \multirow[t]{3}{*}{ Assassinatos de jovens } & & Desperdício de água & & & \\
\hline & & Desmatamento acumulado & & & \\
\hline & & Áreas Protegidas & & & \\
\hline
\end{tabular}

Na dimensão Necessidades Humanas Básicas, Paranã apresentou outros saldos pessimistas nos componentes água e saneamento e moradia adequada, com pontuações de 21,80 e 53,98 respectivamente. Em São Salvador do Tocantins, a segurança pessoal, que engloba homicídios, mortes por acidentes de trânsito e assassinatos de jovens, desponta com pior desempenho $(30,67)$, seguido por água e saneamento $(38,12)$ e moradia $(64,19)$. No elemento nutrição e cuidados médicos básicos, relacionado à mortalidade por desnutrição, materna, infantil e por doenças infecciosas, os resultados apontam para bom nível de progresso social, com pontuações de 75,93, Paranã, e de 75,44, São Salvador do Tocantins (IMAZON et al., 2014). 
A compensação financeira e o desenvolvimento de municípios impactados por hidrelétricas: os indicadores sociais de Paranã e São Salvador do

Tabela 5: IPS Amazônia São Salvador do Tocantins.

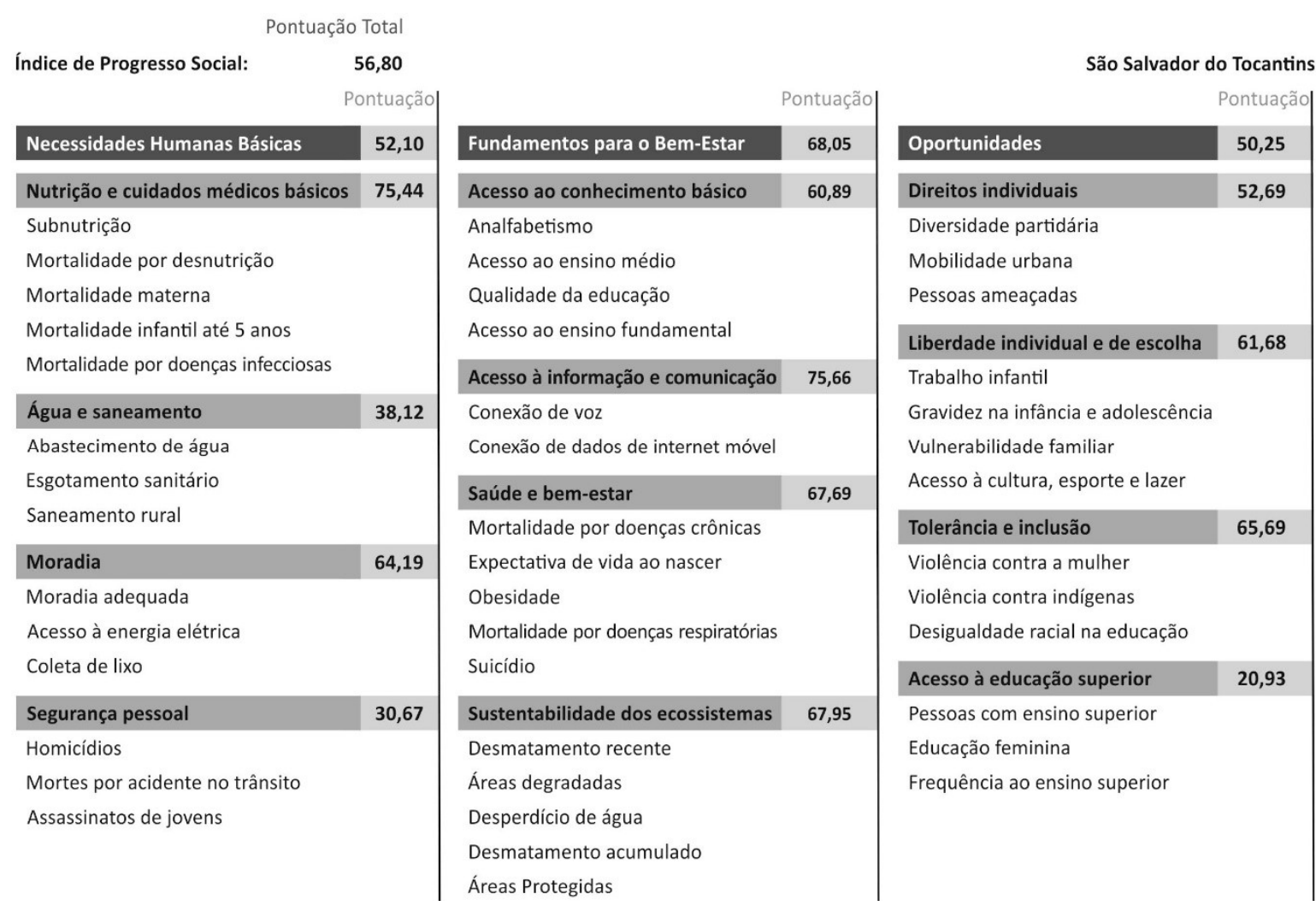

Em termos de Fundamentos para o Bem-Estar, os números indicam condições desfavoráveis no quesito saúde e bem-estar em Paranã, que somou 30,90 pontos. Este indicador, que avalia mortalidade por doenças crônicas e respiratórias, obesidade, taxa de suicídio e expectativa de vida ao nascer, teve melhor resultado em São Salvador do Tocantins, com nota 67,69. 0 acesso ao conhecimento básico também se revelou fraco em Paranã $(55,43)$ e com médio progresso em São Salvador do Tocantins $(60,98)$.

\section{DISCUSSÃO}

Os índices sociais investigados denotam que Paranã e São Salvador do Tocantins apresentam deficiências estruturais e sociais que comprometem a qualidade de vida de suas populações. É fato que o IDH dos municípios melhorou, mas esta foi uma tendência prevista pela criação do Estado do Tocantins em 1988, que impulsionou a implantação de equipamentos públicos, a exemplo de pavimentação de estradas e construção de escolas e hospitais, na área do antigo norte goiano até então carente de políticas públicas e investimentos. De modo geral, todos os municípios tocantinenses avançaram em termos de IDH $\mathrm{H}^{5}$ e de outros indicadores sociais no período que corresponde de 1991 à 2010 (TOCANTINS, 2017).

Os outros dois índices pesquisados, o IBEU Municipal e o IPS Amazônia, revelaram, cada um por meio de sua metodologia, deficiências comuns no que se refere à infraestrutura, oferta de serviços coletivos urbanos, saúde e educação, o que é um indicativo de que, apesar do incremento aos cofres públicos municipais, o dinheiro da CFURH não necessariamente tem se traduzido em compartilhamento de benefícios

\footnotetext{
${ }^{5}$ Progressão do IDH-M (Índice de Desenvolvimento Humano Municipal no Tocantins: $1991=0.369 ; 2000=0,525 ;$ e, $2010=0,699$. Uma evolução de muito baixo para médio desenvolvimento humano (TOCANTINS, 2017).
} 
A compensação financeira e o desenvolvimento de municípios impactados por hidrelétricas: os indicadores sociais de Paranã e São Salvador do

para as comunidades pesquisadas. No período investigado, Paranã com $\mathrm{R} \$ 25,1$ milhões e São Salvador do Tocantins com $\mathrm{R} \$ 12,3$ milhões em verbas destinadas da CFURH, exibem indicadores de bem-estar urbano e progresso social negativos, com reduzida oferta de serviços públicos como fornecimento de água, energia elétrica e esgotamento sanitário inadequados.

Uma das problemáticas acentuadas diz respeito às condições de moradia. As pontuações para o IBEU Municipal, de 0,735 (Paranã) e 0,752 (São Salvador do Tocantins), e do IPS Amazônia, de 53,98 (Paranã) e 64,19 (São Salvador do Tocantins), corroboram com as informações do Censo 2010, que apontou a predominância de moradias em alvenaria sem revestimento em Paranã (1.195 moradias), além de elevado número de habitações construídas com materiais como palha e taipa. Já em São Salvador do Tocantins, apesar de prevalecerem construções em alvenaria com revestimento, ainda existia um número considerável de casas de alvenaria sem revestimento (157 casas) e outras 144 residências construídas com outros materiais que não sejam alvenaria, palha, madeira ou taipa (IBGE, 2012). Os números mostram que a habitação digna, como preconizado pelo Estatuto das Cidades (DIAS, 2010), nas localidades pesquisadas é um direito de apenas uma parcela e não da totalidade dos moradores.

Uma análise detalhada da infraestrutura, outro indicador cujas pontuações tanto do IBEU Municipal quanto pelo IPS Amazônia relevam carências, constata que no ano de 2010 apenas 62,92\% da população de Paranã em domicilio era atendida com energia elétrica e somente $66,91 \%$ com água encanada. Em São Salvador do Tocantins os percentuais destes serviços eram de $76,86 \%$ e $92,01 \%$, respectivamente. Ambas as localidades atendiam a quase à totalidade dos moradores com coleta de lixo (98,11\% - Paranã e 98,06\% - São Salvador do Tocantins), mas o contrário acontecia com o esgotamento sanitário adequado, cujos percentuais apontavam só $0,9 \%$ dos domicílios com este benefício em Paranã e 16,6\% em São Salvador do Tocantins (IBGE, 2012). Os registros do Censo 2010 também revelam limitações acentuadas na variante urbanização das vias públicas, especialmente quanto à inexistência de equipamentos como calçadas, pavimentação, bueiros e meio fio nos dois municípios (IBGE, 2012). As limitações desta área podem ter influenciado diretamente os indicadores de saúde, que em Paranã apresentou muito baixo desempenho, visto que a promoção da saúde depende de variados fatores, desde a alimentação apropriada à assistência médica, condições ambientais e estruturais adequadas (BUSS, 2000).

$\mathrm{Na}$ área social, a investigação identificou "insuficiência de investimentos na qualificação do capital humano" (IMAZON et al., 2014), com notório frágil desempenho da dimensão Oportunidades, relacionada, entre outros aspectos, ao ensino superior e consequente qualificação profissional. Nenhum dos dois municípios conta com faculdades ou universidades, o que força seus moradores a se deslocarem até cidades de maior porte da região sudeste tocantinense para estudar. Este empecilho inibe ou reduz a igualdade de condições entre os cidadãos (BOBBIO, 1993) frente aos desafios e competição da sociedade contemporânea, colaborando para a ampliação das desigualdades sociais. Ressalta-se que, em 2010, Paranã contava com apenas 363 pessoas portadoras de ensino superior completo e em São Salvador do Tocantins eram somente 134 habitantes com este nível de escolaridade (IBGE, 2012). 
A compensação financeira e o desenvolvimento de municípios impactados por hidrelétricas: os indicadores sociais de Paranã e São Salvador do

A média das pontuações das 3 dimensões do IPS Amazônia - Necessidades Humanas Básica, Fundamentos para o Bem-Estar e Oportunidades - foi de 57,31 tanto para Paranã quanto para São Salvador do Tocantins. Este resultado é inferior à média brasileira no período, que foi de 67,53 em 2014 (IMAZON et al., 2014). Simultaneamente, o IBEU Municipal demonstrou condições ruins de bem-estar urbano com as pontuações gerais de 0,697 para Paranã e 0,694 para São Salvador do Tocantins evidenciando desigualdades das condições de bem-estar entre as populações dos espaços urbanos destas localidades (OBSERVATÓRIO DAS METRÓPOLES, 2013).

\section{CONCLUSÕES}

As informações desveladas pela investigação contrapõem-se ao discurso predominante de que as UHEs são propulsoras de desenvolvimento local. Fica evidente que tão importante quanto a liberação de recursos é o planejamento e efetividade da aplicação da CFURH para suprir as necessidades básicas das comunidades afetadas por empreendimentos hidrelétricos. A identificação e análise dos indicadores IBEU Municipal e IPS Amazônia revelaram desenvolvimento social insatisfatório tanto em Paranã quanto em São Salvador do Tocantins, com os municípios apresentando deficiências de infraestrutura, com oferta inadequada de serviços como energia elétrica e esgotamento sanitário, além de déficits nas condições de moradia e na assistência à saúde, áreas que deveriam ser prioritárias para investimentos dos recursos derivados das compensações financeiras em uma década. A estes aspectos, acrescenta-se a limitada oferta de oportunidades de evolução educacional e profissional dos moradores destas localidades, o que agrava a conjuntura de desigualdades, comprometendo o bem-estar e progresso social das comunidades. Os resultados da pesquisa evidenciam a necessidade de se aprimorar os mecanismos de regulamentação do uso do dinheiro proveniente da CFURH. Nesse sentido, faz-se necessário a adoção de uma legislação que, por meio de regras formais, condicione a aplicação da verba estritamente a políticas públicas e sociais relevantes para a o bem-estar da população e que, ao mesmo tempo, exija uma prestação de contas transparente por parte do poder público.

\section{REFERÊNCIAS}

ANEEL. Agência Nacional de Energia Elétrica. Compensação Financeira pela Utilização de Recursos Hídricos para Geração de Energia Elétrica. Brasília, 2005.

ANEEL. Agência Nacional de Energia Elétrica. A compensação Financeira e o seu município. Brasília, 2007

ANEEL. Agência Nacional de Energia Elétrica. Relatórios da Compensação Financeira pela Utilização de Recursos Hídricos (CFURH). Brasília, 2018.

BERMANN, C.. Impasses e controvérsias da hidroeletricidade. Revista Estudos Avançados, v.21, n.59, 2007.

BOBBIO, H.. Igualdad y libertad. Barcelona: Paidós Ibérica, 1993.
BRASIL. Boletim Mensal de Monitoramento do Setor Elétrico Brasileiro. Ministério de Minas e Energia, Brasília, dezembro, 2018.

BRASIL. Lei 13.661: Altera a Lei no 8.001, de 13 de março de 1990, para definir as parcelas pertencentes aos Estados e aos Municípios do produto da Compensação Financeira pela Utilização de Recursos Hídricos (CFURH). Brasília: DOU, 2018

BRASIL. Plano Decenal de Expansão de Energia 2024.

Brasília: Ministério de Minas e Energia, 2015.

BUSS, P. M.. Promoção da saúde e qualidade de vida.

Revista Ciência \& Saúde Coletiva, v.5, n.1, p.163-177, 2000. 
CERNEA, M. M.. Compensation and benefit sharing: Why resettlement policies and practices must be reformed.

Water Science and Engineering, v.1, n.1, p.89-120, 2008.

DIAS, D. S.. O direito à moradia digna e a eficácia dos direitos fundamentais sociais. Revista do Ministério Público do Estado do Pará, v.1, n.5, 2010.

EPE. Empresa de Pesquisa Energética. Avaliação Ambiental dos Aproveitamentos Hidrelétricos da Bacia do Rio Tocantins: Avaliação Ambiental Distribuída e Conflitos. 2007.

FARIA, R. C.; KNIESS, C. T.; MACCARI, E. A.. Sustentabilidade em Grandes Usinas Hidrelétricas. Revista de Gestão e Projetos, v.3, n.1, p.225-251, 2012.

GOMES, C. S.; ROQUETTI, D. R.; PULICE, S. M. P.; MORETTO, E. M.. Usinas Hidrelétricas e o Desenvolvimento Municipal: O Caso das Usinas Hidrelétricas do Complexo PelotasUruguai. Revista de Gestão Ambiental e Sustentabilidade, v.6, n.2, 2017.

IBGE. Instituto Brasileiro de Geografia e Estatística. Censo Demográfico Brasileiro de 2010. Rio de Janeiro: IBGE, 2012.

IMAZON; PROGRESSO SOCIAL BRASIL. Índice de Progresso Social na Amazônia Brasileira: IPS Amazônia 2014. Scorecards Estado do Tocantins. 2014.

MOREIRA, S. V.. Análise documental como método e como técnica. In: JORGE, D.; BARROS, A.. Métodos e Técnicas de pesquisa em comunicação. São Paulo: Atlas, 2005.
OBSERVATÓRIO DAS METRÓPOLES. IBEU: Índice de BemEstar Urbano. Rio de Janeiro: Letra Capital, 2013.

OBSERVATÓRIO DAS METRÓPOLES. IBEU Municipal: Índice de Bem-Estar Urbano dos Municípios Brasileiros. Rio de Janeiro: Letra Capital, 2016.

PNUD. Índice de Desenvolvimento Humano Municipal Brasileiro. Brasília: PNUD, 2013.

PULICE, S. M. P.; MORETTO, E. M.. A Compensação Financeira e o Desenvolvimento dos Municípios Brasileiros Alagados por Usinas Hidrelétricas. Revista Ambiente e Sociedade, São Paulo, v.20, n.4, p.107-130, 2017.

SILVA, L. L.. A compensação financeira das usinas hidrelétricas como instrumento econômico de desenvolvimento social, econômico e ambiental. Dissertação (Mestrado em Gestão Econômica do Meio Ambiente) - Universidade de Brasília, Brasília, 2007.

STERCHILE, S. P. W.; SOUZA, E. B. C.. Apontamentos sobre a aplicação dos royalties da Itaipu Binacional e o processo de desenvolvimento. Revista Brasileira de Gestão e

Desenvolvimento Regional, Taubaté, v.4, n.2, p.3-22, 2008.

TOCANTINS. Atlas do Tocantins: Subsídios ao planejamento da gestão Territorial. Palmas: Secretaria do Planejamento e da Modernização da Gestão Pública, 2012.

TOCANTINS. Indicadores Socioeconômicos do Estado do Tocantins. Palmas: Secretaria do Planejamento e Orçamento, 2017.

A CBPC - Companhia Brasileira de Produção Científica (CNPJ: 11.221.422/0001-03) detém os direitos materiais desta publicação. Os direitos referem-se à publicação do trabalho em qualquer parte do mundo, incluindo os direitos às renovações, expansões e disseminações da contribuição, bem como outros direitos subsidiários. Todos os trabalhos publicados eletronicamente poderão posteriormente ser publicados em coletâneas impressas sob coordenação da Sustenere Publishing, da Companhia Brasileira de Produção Científica e seus parceiros autorizados. Os (as) autores (as) preservam os direitos autorais, mas não têm permissão para a publicação da contribuição em outro meio, impresso ou digital, em português ou em tradução. 